\title{
Improvement of Propylene Epoxidation Caused by Silver Plasmon Excitation by UV-LED Irradiation on a Sodium-Modified Silver Catalyst Supported on Strontium Carbonate
}

\author{
Shigeru Sugiyama ${ }^{1, *}$, Ikumi Okitsu ${ }^{2}$, Kazuki Hashimoto ${ }^{3}$, Yutaro Maki ${ }^{4}$, Naohiro Shimoda ${ }^{1}$, Akihiro Furube ${ }^{5}$, \\ Yuki Kato ${ }^{6}$ and Wataru Ninomiya ${ }^{6}$
}

1 Department of Applied Chemistry, Tokushima University, Minamijosanjima, Tokushima-shi, Tokushima 770-8506, Japan; shimoda@tokushima-u.ac.jp

2 Department of Chemical Science and Technology, Tokushima University, Minamijosanjima, Tokushima-shi, Tokushima 770-8506, Japan; c.1935.okkeyy@gmail.com

3 Department of Science and Technology, Tokushima University, Minamijosanjima, Tokushima-shi, Tokushima 770-8506, Japan; groundgm07@gmail.com

4 Department of Optical System Engineering, Tokushima University, Minamijosanjima, Tokushima-shi, Tokushima 770-8506, Japan; yutaro.baseball@gmail.com

check for updates

Citation: Sugiyama, S.; Okitsu, I.; Hashimoto, K.; Maki, Y.; Shimoda, N.; Furube, A.; Kato, Y.; Ninomiya, W. Improvement of Propylene Epoxidation Caused by Silver Plasmon Excitation by UV-LED Irradiation on a Sodium-Modified Silver Catalyst Supported on Strontium Carbonate. Catalysts 2021, 11, 398. https://doi.org/10.3390/ catal11030398

Academic Editors: Sébastien Leveneur, Vincenzo Russo and Pasi Tolvanen

Received: 9 March 2021

Accepted: 19 March 2021

Published: 21 March 2021

Publisher's Note: MDPI stays neutral with regard to jurisdictional claims in published maps and institutional affiliations.

Copyright: (C) 2021 by the authors. Licensee MDPI, Basel, Switzerland. This article is an open access article distributed under the terms and conditions of the Creative Commons Attribution (CC BY) license (https:// creativecommons.org/licenses/by/ $4.0 /)$.
5 Department of Optical Science, Tokushima University, Minamijosanjima, Tokushima-shi, Tokushima 770-8506, Japan; furube.akihiro@tokushima-u.ac.jp

6 Hiroshima R\&D Center, Mitsubishi Chemical Corporation, 20-1, Miyuki-cho, Otake-shi, Hiroshima 739-0693, Japan; yuki.ma@m-chmical.co.jp (Y.K.); ninomiya.wataru.me@m-chemical.co.jp (W.N.)

* Correspondence: sugiyama@tokushima-u.ac.jp; Tel.: +81-88-656-7432

\begin{abstract}
The effect that UV-LED irradiation exerted on a sodium-modified silver catalyst supported on strontium carbonate $\left(\mathrm{Ag}-\mathrm{Na} / \mathrm{SrCO}_{3}\right)$ was examined during an epoxidation of propylene to propylene oxide. Based on our previous study, we used $\mathrm{Ag}(56)-\mathrm{Na}(1) / \mathrm{SrCO}_{3}$ in this study. The numbers in parentheses refer to the weight percentage of silver and sodium. Although this catalyst system did not contain typical photocatalysts such as titanium oxide or tungsten oxide, UV-LED irradiation of $\mathrm{Ag}(56)-\mathrm{Na}(1) / \mathrm{SrCO}_{3}$ resulted in an evident improvement in the selectivity and yield of propylene oxide. Such an advantageous effect of UV-LED irradiation could not be discussed based on the bandgap used in photocatalysts and, therefore, we proposed a mechanism based on the plasmon excitation of silver, which could be accomplished using the irradiation wavelength of UV-LED to produce electrons. Since the lifespan of these electrons is expected to be short, it is difficult to place them into direct contact with the gas phase of oxygen. Once the generated electrons move to $\mathrm{SrCO}_{3}$, however, the lifespan is improved, which could allow suitable contact with oxygen in the gas phase to form active oxygen. If the oxygen is active for epoxidation as hydrogen peroxide, this could explain the improvement in activity from UV-LED irradiation.
\end{abstract}

Keywords: epoxidation; propylene; propylene oxide; UV-LED; plasmon excitation; silver catalyst

\section{Introduction}

Since propylene oxide is a raw material for polyurethane that is widely used in automobile parts, food additives, cosmetics, etc., more than 10 million tons are produced annually worldwide by the petrochemical industry [1]. At present, $40 \%$ of this production is via the classical production method, the chlorohydrin method, but the construction of new plants has been suppressed due to concerns over environmental pollution [1,2]. The Halcon process has subsequently been developed and has overcome the shortcomings of the chlorohydrin method. However, since the Halcon process is a co-production method, it is greatly affected by the demand for by-products [2,3]. Currently, the cumene method, which overcomes this point, is being developed as a single production method for propylene 
oxide [1-3]. Although not yet industrialized, a method for producing propylene oxide by epoxidation of propylene (Equation (1)) has been widely studied in academia as a simple, economical, and energetically ideal method for producing propylene oxide [4-6]. As shown in our previous paper [7], the activity of catalytic systems tends to be overestimated. Moreover, this epoxidation is classified as a highly difficult oxidation reaction, and in order to improve the production of propylene oxide and the development of catalysts, novel methods and concepts must be introduced into ordinary reaction fields.

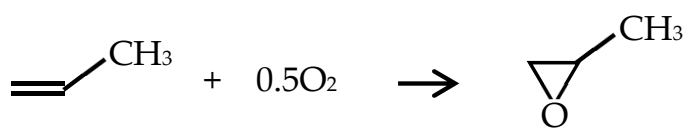

Against this background, we examined the catalytic epoxidation of propylene to propylene oxide under UV-LED irradiation conditions, and noted the effect that UV-LED irradiation exerts on epoxidation. Prior to the present study, we investigated the partial oxidation of methane under UV-LED irradiation conditions using a samarium oxide catalyst doped with an anatase type of titanium oxide [8]. Samarium oxide is a suitable catalyst for the oxidative coupling of methane. When titanium oxide was added to samarium oxide, however, partial oxidation of methane to carbon monoxide occurred preferentially under UV-LED irradiation conditions. The effect of active oxygen such as $\mathrm{O}_{2}{ }^{-}$generated under UV-LED irradiation conditions was clearly reflected in the catalytic activity. In the present study, therefore, we investigated the effect that UV-LED irradiation exerts on the activity of a sodium-modified silver catalyst supported on strontium carbonate (Ag-Na/ $\left.\mathrm{SrCO}_{3}\right)$. Although the activity of this catalyst was low, we have already found that similar results were obtained when similar methods of this catalyst preparation and activity test were performed in different laboratories, as shown in a previous study [7]. Furthermore, we confirmed that the use of this catalyst could avoid the overestimation of catalytic activity [7]. In a manner similar to the partial oxidation reaction of methane, we attempted to examine the effect of UV-LED irradiation by adding normal photocatalysts such as titanium oxide or tungsten oxide to an $\mathrm{Ag}-\mathrm{Na} / \mathrm{SrCO}_{3}$ catalyst. There was no effect from UV-LED when the photocatalyst was added, but there was a clear improvement in the selectivity and yield of propylene oxide when a photocatalyst was not added. Therefore, in the present study, we examined the activity on $\mathrm{Ag}-\mathrm{Na} / \mathrm{SrCO}_{3}$ in the absence of a photocatalyst under UV-LED irradiation.

\section{Results and Discussion}

\subsection{Effect of UV-LED Irradiation on Catalytic Behavior}

Figure 1 depicts the use of UV-LED irradiation for the epoxidation of propylene to propylene oxide (PO) and shows the effects on $\mathrm{Ag}(56)-\mathrm{Na}(1) / \mathrm{SrCO}_{3}(0.3 \mathrm{~g})$ at $\mathrm{F}=15 \mathrm{~mL} / \mathrm{min}$, $\mathrm{p}\left(\mathrm{C}_{3} \mathrm{H}_{6}\right)=\mathrm{p}\left(\mathrm{O}_{2}\right)=16.9 \mathrm{kPa}$ and $673 \mathrm{~K}$, which was the starting point for the present study. In the present study, we focused on the behavior of propylene, oxygen and PO. Under the reaction conditions employed in the present study, $\mathrm{CO}_{2}, \mathrm{CO}$, propane, acetaldehyde, propionaldehyde and acrolein were detected in proportional ranges of $81.9-97.6 \%, 0.0-9.6 \%$, $0.3-8.3 \%, 0.0-3.4 \%, 0.0-0.9 \%$ and $0.0-1.0 \%$, respectively, in terms of selectivity. As shown in Figure 1, without UV-LED irradiation, the rate of the selectivity and yield of $\mathrm{PO}$ at $0.5 \mathrm{~h}$ on-stream were 1.2 and $0.04 \%$, respectively, followed by slight enhancements in the PO yield to $0.10 \%$ at $1.75 \mathrm{~h}$ on-stream. Following irradiation using UV-LED, the selectivity and yield of $\mathrm{PO}$ at $0.5 \mathrm{~h}$ on-stream were evidently enhanced to 1.7 and $0.07 \%$ at $0.75 \mathrm{~h}$ onstream, followed by additional enhancement to 3.4 and $0.42 \%$ at $1.75 \mathrm{~h}$ on-stream. Almost the same effect of UV-LED irradiation on the selectivity and yield of $\mathrm{PO}$ was detected at $\mathrm{p}\left(\mathrm{C}_{3} \mathrm{H}_{6}\right)=33.8 \mathrm{kPa}, \mathrm{p}\left(\mathrm{O}_{2}\right)=16.9 \mathrm{kPa}$ and $673 \mathrm{~K}$. Without UV-LED under $\mathrm{C}_{3} \mathrm{H}_{6}$ rich conditions, the selectivity and yield of $\mathrm{PO}$ were 0.4 and $0.02 \%$, respectively, at $1.75 \mathrm{~h}$ onstream. It is noteworthy that, with UV-LED, the selectivity and yield of PO were similarly improved to 2.3 and $0.15 \%$, respectively, at $1.75 \mathrm{~h}$ on-stream. It should be noted that the most important effect of UV-LED irradiation is the increase in the selectivity of PO, 
followed by the increase in the yield of PO. Although the effect of UV-LED irradiation as an accelerant of the epoxidation of propylene on $\mathrm{Ag}(56)-\mathrm{Na}(1) / \mathrm{SrCO}_{3}$ was evident, and it became necessary to examine whether this improvement would continue even if the time-on-stream was extended. Therefore, another test sample of $\mathrm{Ag}(56)-\mathrm{Na}(1) / \mathrm{SrCO}_{3}$ was prepared separately and examined for up to $6 \mathrm{~h}$ on-stream.

Figure 2 shows the results obtained on $\mathrm{Ag}(56)-\mathrm{Na}(1) / \mathrm{SrCO}_{3}$ and $\mathrm{Ag}(75)-\mathrm{Na}(1) / \mathrm{SrCO}_{3}$ during $6 \mathrm{~h}$ on-stream under the same reaction conditions as those in Figure 1 under UV-LED irradiation conditions.

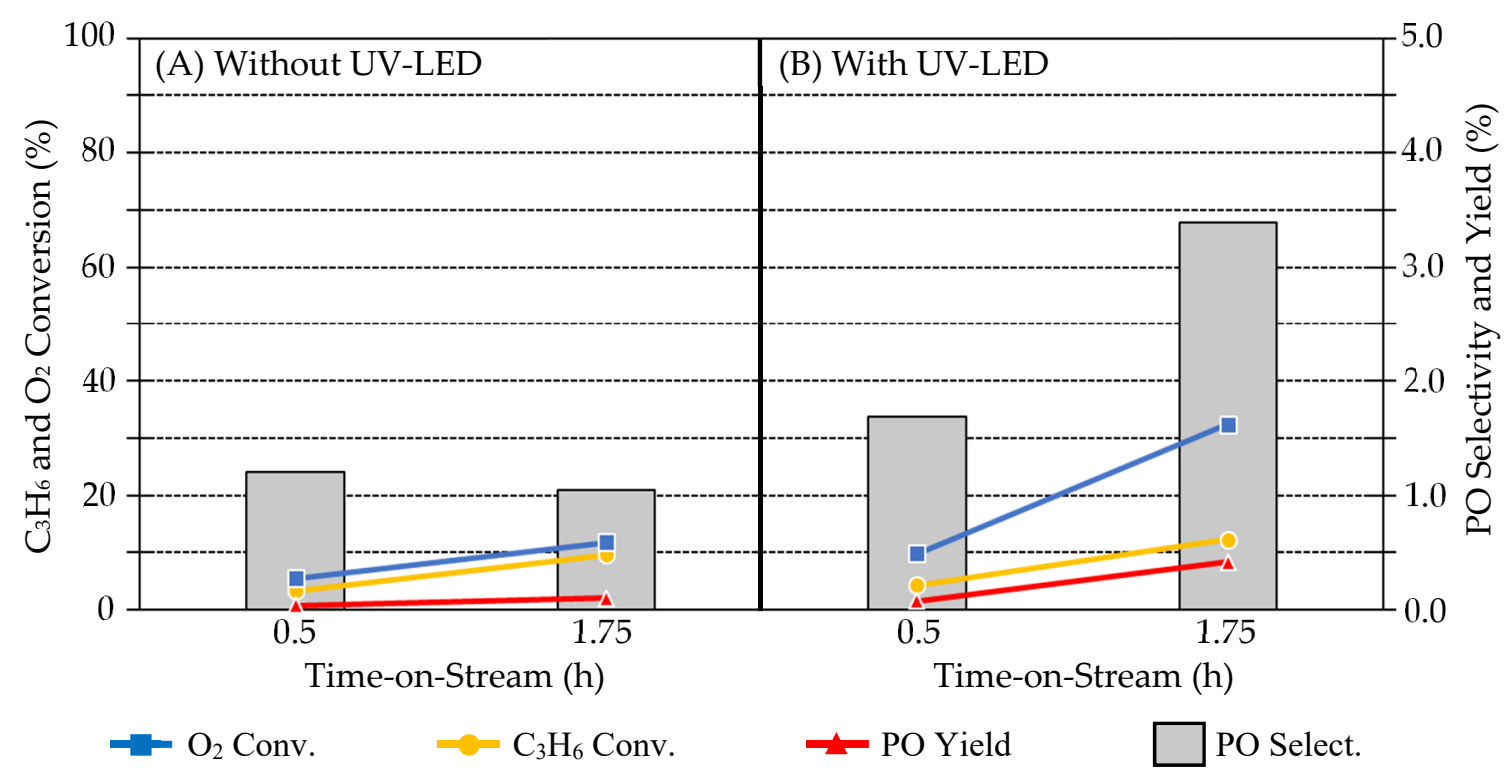

Figure 1. Effect of UV-LED irradiation on catalytic activity on $\mathrm{Ag}(56)-\mathrm{Na}(1) / \mathrm{SrCO}_{3}(0.30 \mathrm{~g})$ at $\mathrm{F}=15 \mathrm{~mL} / \mathrm{min}$, $\mathrm{p}\left(\mathrm{C}_{3} \mathrm{H}_{6}\right)=\mathrm{p}\left(\mathrm{O}_{2}\right)=16.9 \mathrm{kPa}$ and $673 \mathrm{~K}$.

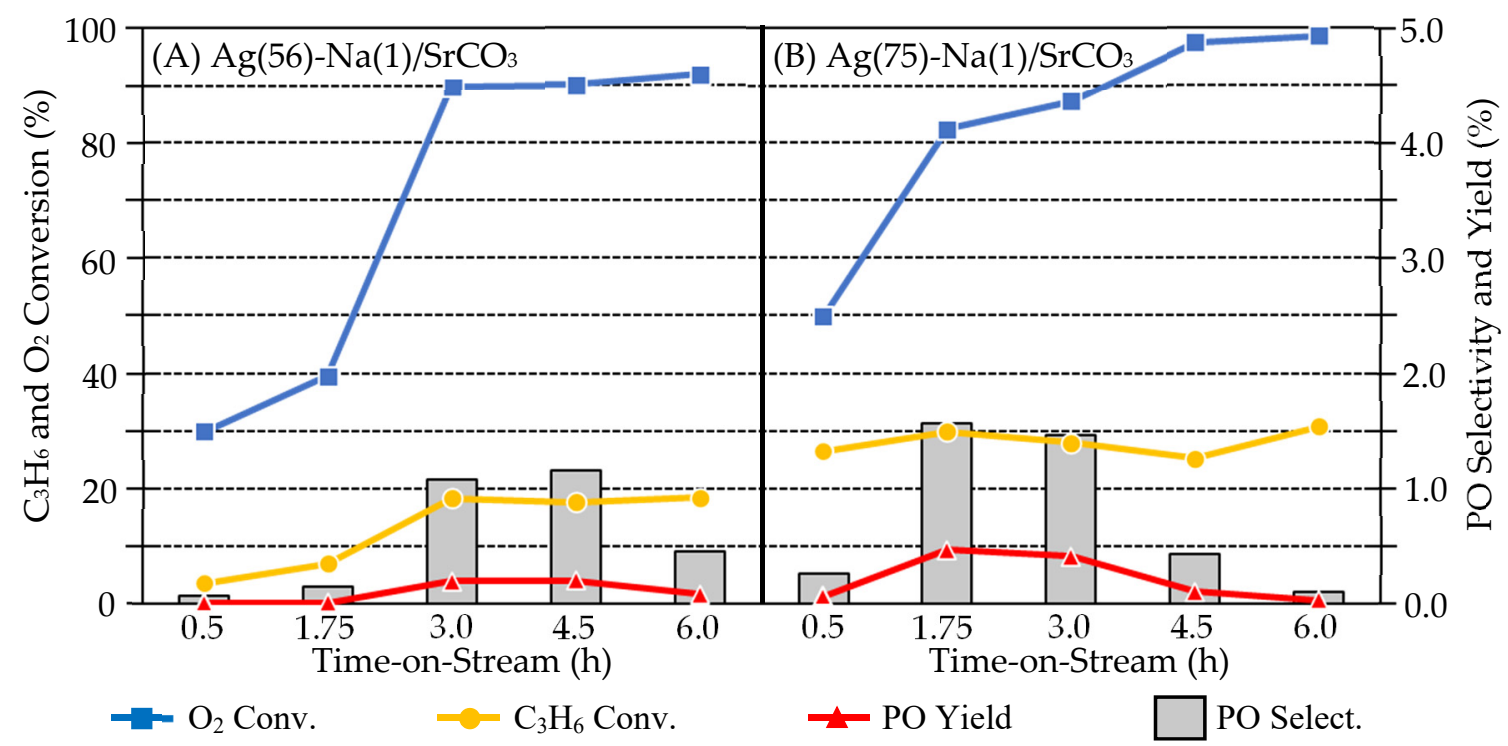

Figure 2. Catalytic activity on $\mathrm{Ag}(56)-\mathrm{Na}(1) / \mathrm{SrCO}_{3}$ and $\mathrm{Ag}(75)-\mathrm{Na}(1) / \mathrm{SrCO}_{3}$ (both $0.30 \mathrm{~g}$ ) at $\mathrm{F}=15 \mathrm{~mL} / \mathrm{min}$, $\mathrm{p}\left(\mathrm{C}_{3} \mathrm{H}_{6}\right)=\mathrm{p}\left(\mathrm{O}_{2}\right)=16.9 \mathrm{kPa}$ and $673 \mathrm{~K}$ under UV-LED irradiation.

As expected from the previous report [9], since the formation of $\mathrm{PO}$ was difficult to confirm on $\mathrm{Ag}(25)-\mathrm{Na}(1) / \mathrm{SrCO}_{3}$, we focus on the former two catalysts in the present paper.

The catalytic activity on the newly prepared $\mathrm{Ag}(56)-\mathrm{Na}(1) / \mathrm{SrCO}_{3}$ was lower than that in Figure 1, since the catalyst preparation method was greatly affected by slight differences 
in the conditions. However, the improvement behavior of the activity by UV-LED with time-on-stream was again observed. As shown in Figure 2, the selectivity and yield of PO on $\mathrm{Ag}(75)-\mathrm{Na}(1) / \mathrm{SrCO}_{3}$ was evidently greater than that on $\mathrm{Ag}(56)-\mathrm{Na}(1) / \mathrm{SrCO}_{3}$ regardless of time-on-stream, indicating that the contribution of silver to the catalytic activity was evident. Although the $\mathrm{PO}$ yield was unavoidably low for the epoxidation of propylene to $\mathrm{PO}$, we focused on the selectivity and yield of $\mathrm{PO}$ with time-on-stream on both catalysts. On $\mathrm{Ag}(56)-\mathrm{Na}(1) / \mathrm{SrCO}_{3}$, the selectivity and yield of $\mathrm{PO}$ increased to 1.2 and $0.20 \%$ at $4.5 \mathrm{~h}$ on-stream, while the increase was 1.6 and $0.47 \%$ at $1.75 \mathrm{~h}$ on-stream on $\mathrm{Ag}(75)$ $\mathrm{Na}(1) / \mathrm{SrCO}_{3}$, and both were followed by decreases in both the selectivity and yield of PO. It should be noted that the selectivity and yield on $\mathrm{Ag}(56)-\mathrm{Na}(1) / \mathrm{SrCO}_{3}$ was 0.5 and $0.05 \%$, respectively, once UV-LED irradiation was interrupted at $3 \mathrm{~h}$ on-stream. Although $\mathrm{Ag}(56)-\mathrm{Na}(1) / \mathrm{SrCO}_{3}$ and $\mathrm{Ag}(75)-\mathrm{Na}(1) / \mathrm{SrCO}_{3}$ contained no typical photocatalysts such as titanium oxide or tungsten oxide, the improvement in activity from UV-LED irradiation was evident. Therefore, it was necessary to establish whether the influence of this UV-LED irradiation was due to the $\mathrm{Ag}-\mathrm{Na} / \mathrm{SrCO}_{3}$ catalyst itself or to the constituent species of this catalyst.

\subsection{Effect of UV-LED Irradiation on the Components of $\mathrm{Ag}-\mathrm{Na} / \mathrm{SrCO}_{3}$ and that on $\mathrm{Ag}-\mathrm{Na} / \mathrm{MgCO}_{3}$}

The effects that UV-LED irradiation exerted on the catalytic activity of $\mathrm{SrCO}_{3}$ (A), $\mathrm{Ag} / \mathrm{SrCO}_{3}(\mathrm{~B})$, and $\mathrm{Na} / \mathrm{SrCO}_{3}(\mathrm{C})$ together with $\mathrm{Ag}-\mathrm{Na} / \mathrm{MgCO}_{3}(\mathrm{D})$ were examined and the results are described in Table 1.

Table 1. Effect of catalytic activity under UV-LED irradiation on $\mathrm{SrCO}_{3}(\mathrm{~A}), \mathrm{Ag}(56) / \mathrm{SrCO}_{3}$ (B), $\mathrm{Na}(1) / \mathrm{SrCO}_{3}$ (C), and $\mathrm{Ag}(56)-\mathrm{Na}(1) / \mathrm{MgCO}_{3}$ (D) (all at $0.30 \mathrm{~g}$ ) at $\mathrm{F}=15 \mathrm{~mL} / \mathrm{min}$, $\mathrm{p}\left(\mathrm{C}_{3} \mathrm{H}_{6}\right)=\mathrm{p}\left(\mathrm{O}_{2}\right)=16.9 \mathrm{kPa}$ and $673 \mathrm{~K}$.

\begin{tabular}{ccccc}
\hline Catal. & Time-on-Stream (h) & $\mathrm{C}_{3} \mathbf{H}_{\mathbf{6}}$ Conv. (\%) & PO Select. (\%) & PO Yield (\%) \\
\hline \multirow{3}{*}{ (A) } & 0.5 & 3.5 & 0.0 & 0.0 \\
& 1.75 & 6.6 & 0.0 & 0.0 \\
& 3.0 & 7.6 & 0.0 & 0.0 \\
\hline & 0.5 & 13.8 & 0.0 & 0.0 \\
& 1.75 & 15.7 & 0.0 & 0.0 \\
& 3.0 & 16.4 & 0.0 & 0.0 \\
\hline & 0.5 & 4.6 & 1.3 & 0.06 \\
& 1.75 & 5.7 & 0.0 & 0.0 \\
& 3.0 & 8.8 & 0.0 & 0.0 \\
\hline & 0.5 & 24.1 & 0.0 & 0.01 \\
(D) & 1.75 & 33.1 & 0.0 & 0.01 \\
& 3.0 & 28.4 & 0.0 & 0.01 \\
\hline
\end{tabular}

It was evident that the $\mathrm{SrCO}_{3}$ support alone (catalyst (A)) showed no activity for the epoxidation of propylene under UV-LED irradiation conditions. With the loading of silver on $\mathrm{SrCO}_{3}$ (catalyst (B)), the conversion of propylene was evidently enhanced but, again, the effect of UV-LED irradiation was negligible. The loading of sodium onto $\mathrm{SrCO}_{3}$ resulted in only a slight improvement in activity while the effect of UV-LED irradiation also was negligible. Changing the support from $\mathrm{SrCO}_{3}$ to $\mathrm{MgCO}_{3}$ resulted in no effect from UV-LED irradiation and, instead, it prevented the production of PO. Therefore, the effect of UV-LED irradiation on the epoxidation of propylene to $\mathrm{PO}$ observed in the present study appeared to be dependent on the interactions of each of the components of the $\mathrm{Ag}(56)-\mathrm{Na}(1) / \mathrm{SrCO}_{3}$ catalyst.

\subsection{Characterization of the $\mathrm{Ag}-\mathrm{Na} / \mathrm{SrCO} \mathrm{CO}_{3}$ Catalyst}

The specific surface areas of $\mathrm{Ag}(56)-\mathrm{Na}(1) / \mathrm{SrCO}_{3}$ and $\mathrm{Ag}(75)-\mathrm{Na}(1) / \mathrm{SrCO}_{3}$ were 2.2 and $1.3 \mathrm{~m}^{2} / \mathrm{g}$. As shown in the XRD patterns of $\mathrm{Ag}(75)-\mathrm{Na}(1) / \mathrm{SrCO}_{3}$ (Figure 3), only the signals due to metallic silver (PDF 01-087-0597) were detected before and after epoxidation 
under UV-LED irradiation. Furthermore, the SEM images of $\mathrm{Ag}(75)-\mathrm{Na}(1) / \mathrm{SrCO}_{3}$ (Figure 4) revealed no structural changes such as sintering or transformation to other species either before or after epoxidation, while a covering on the surface by coking was detected.

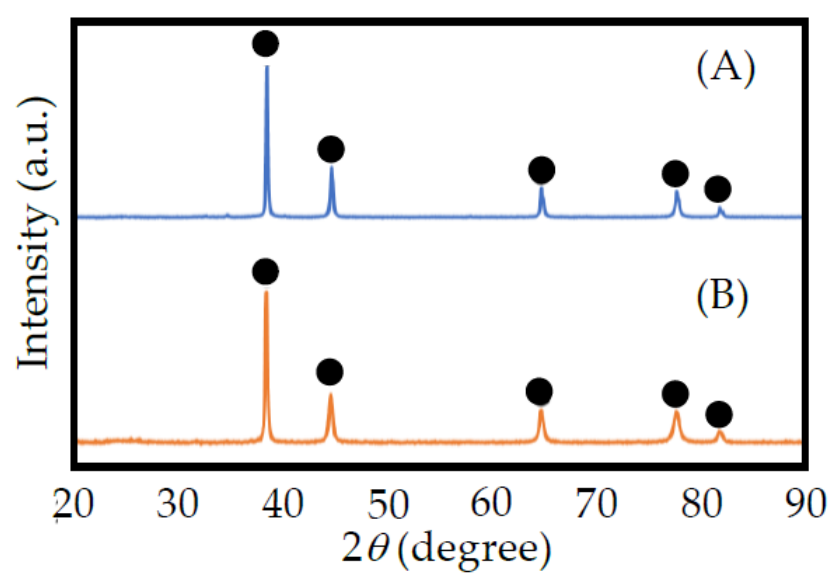

Figure 3. XRD Patterns of $\mathrm{Ag}(75)-\mathrm{Na}(1) / \mathrm{SrCO}_{3}$ (A) before and $(\mathbf{B})$ after epoxidation at $\mathrm{F}=15 \mathrm{~mL} / \mathrm{min}$, $\mathrm{p}\left(\mathrm{C}_{3} \mathrm{H}_{6}\right)=\mathrm{p}\left(\mathrm{O}_{2}\right)=16.9 \mathrm{kPa}$ and $673 \mathrm{~K}$ under UV-LED conditions. $\bullet: \mathrm{Ag}$

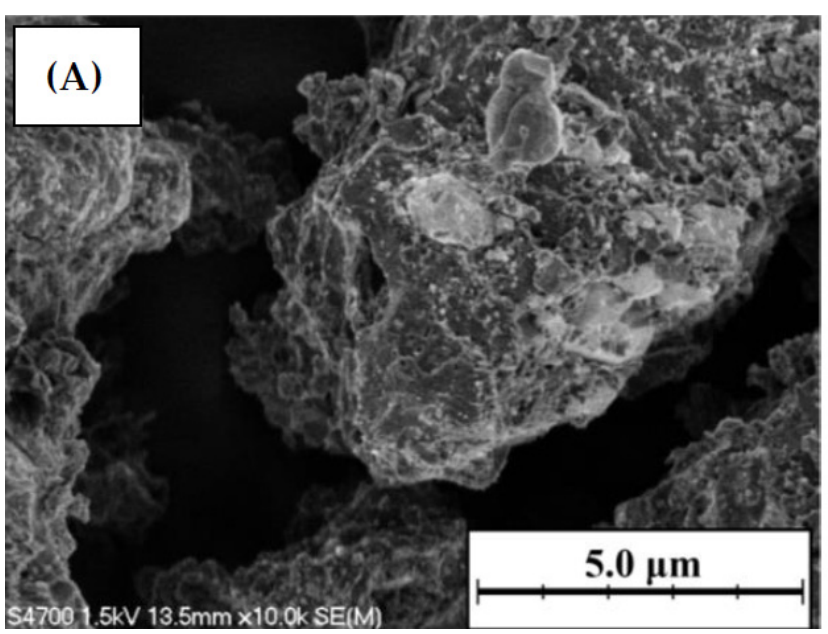

Figure 4. SEM images of $\mathrm{Ag}(75)-\mathrm{Na}(1) / \mathrm{SrCO}_{3}$ (A) before and (B) after epoxidation at $\mathrm{F}=15 \mathrm{~mL} / \mathrm{min}$, $\mathrm{p}\left(\mathrm{C}_{3} \mathrm{H}_{6}\right)=\mathrm{p}\left(\mathrm{O}_{2}\right)=16.9 \mathrm{kPa}$ and $673 \mathrm{~K}$ under UV-LED conditions.

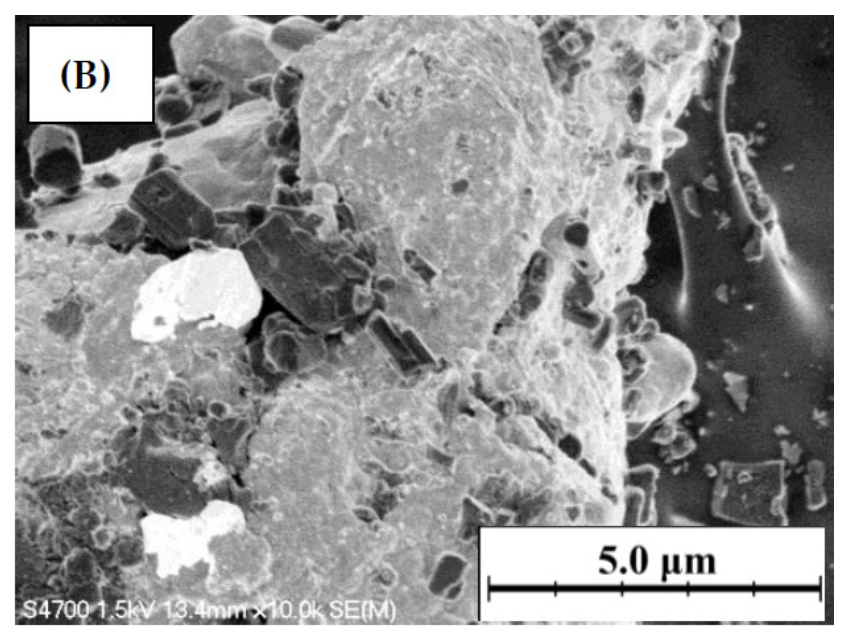

The coking was further supported by changes in the acidic and basic properties of the $\mathrm{Ag}(75)-\mathrm{Na}(1) / \mathrm{SrCO}_{3}$ catalyst before and after epoxidation. Figures 5 and 6 show the $\mathrm{NH}_{3}$ - and $\mathrm{CO}_{2}$-TPD of $\mathrm{Ag}(56)-\mathrm{Na}(1) / \mathrm{SrCO}_{3}$ and $\mathrm{Ag}(75)-\mathrm{Na}(1) / \mathrm{SrCO}_{3}$ before and after epoxidation. Based on Figure 5, the maximum $\mathrm{NH}_{3}$-TPD peaks of $\mathrm{Ag}(56)-\mathrm{Na}(1) / \mathrm{SrCO}_{3}$ and $\mathrm{Ag}(75)-\mathrm{Na}(1) / \mathrm{SrCO}_{3}$ before the reaction were detected at 755 and $736 \mathrm{~K}$, respectively, and the amounts of acid were estimated to be 0.023 and $0.013 \mathrm{mmol} / \mathrm{g}$, respectively. 


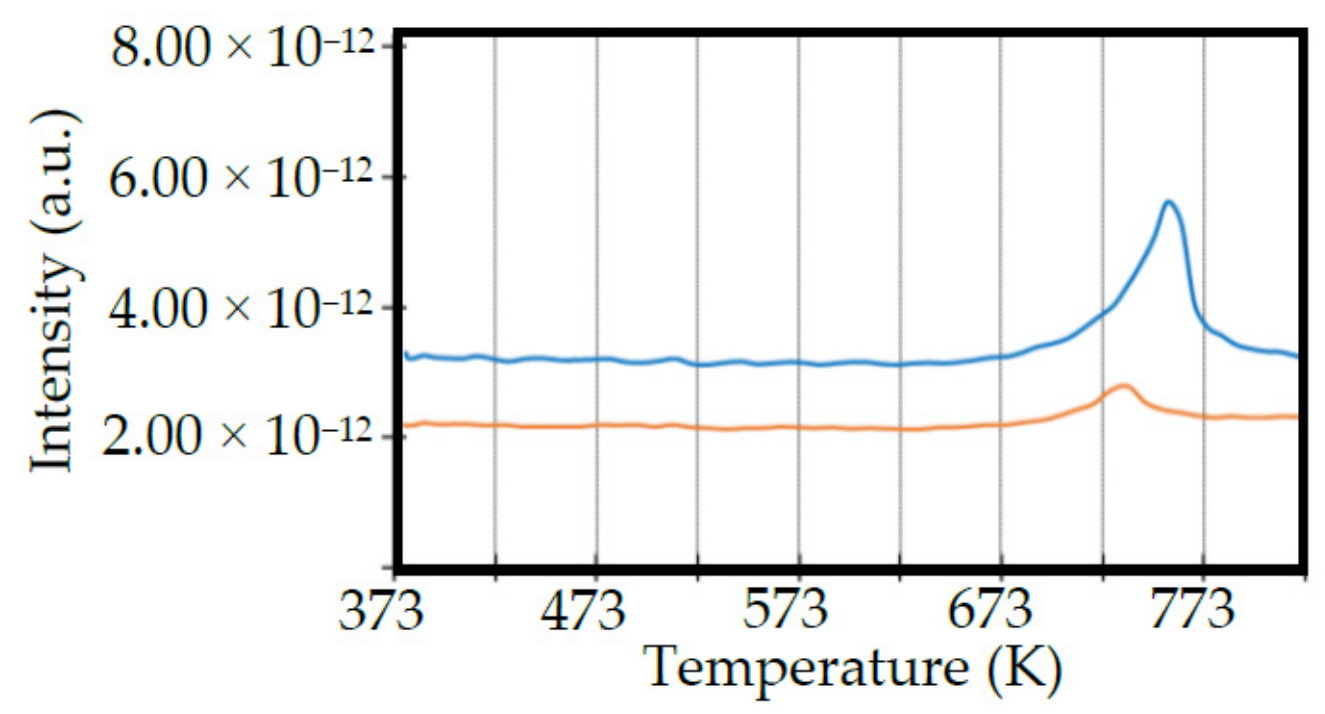

Figure 5. $\mathrm{NH}_{3}-\mathrm{TPD}$ of $\mathrm{Ag}(56)-\mathrm{Na}(1) / \mathrm{SrCO}_{3}$ (blue line) and $\mathrm{Ag}(75)-\mathrm{Na}(1) / \mathrm{SrCO}_{3}$ (orange line) before epoxidation at $\mathrm{F}=15 \mathrm{~mL} / \mathrm{min}, \mathrm{p}\left(\mathrm{C}_{3} \mathrm{H}_{6}\right)=\mathrm{p}\left(\mathrm{O}_{2}\right)=16.9 \mathrm{kPa}$ and $673 \mathrm{~K}$.

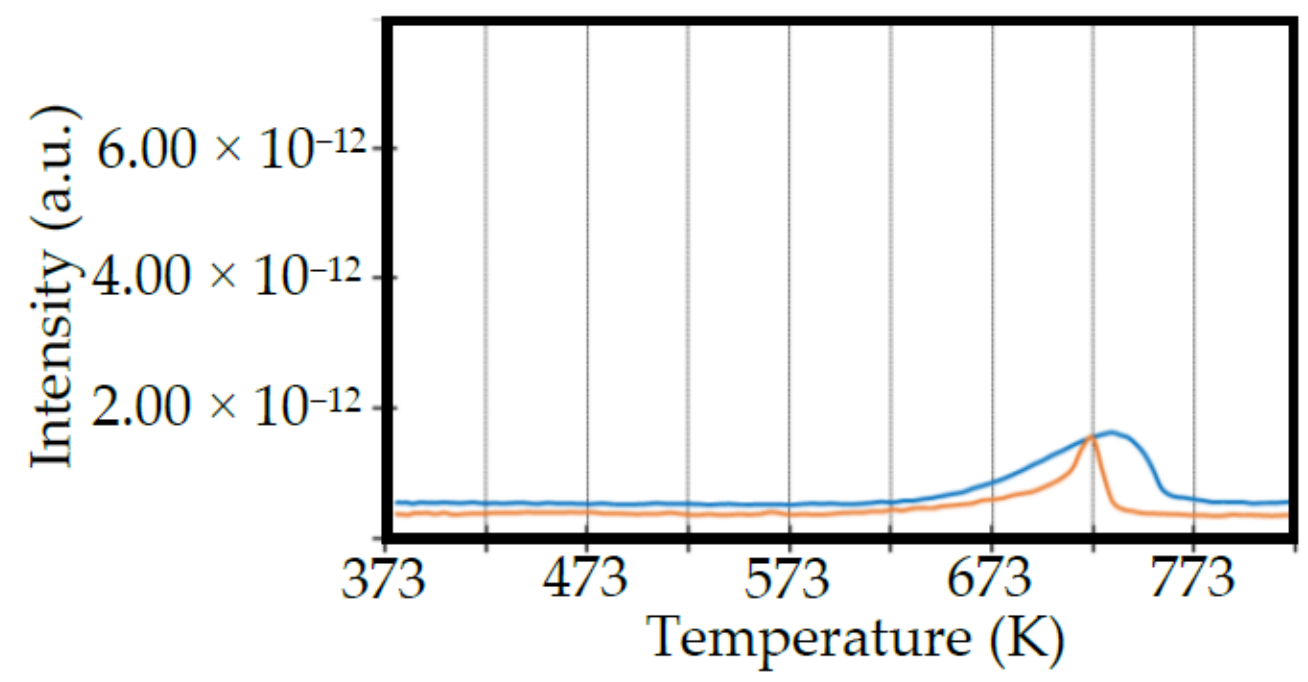

Figure 6. $\mathrm{CO}_{2}-\mathrm{TPD}$ of $\mathrm{Ag}(56)-\mathrm{Na}(1) / \mathrm{SrCO}_{3}$ (blue line) and $\mathrm{Ag}(75)-\mathrm{Na}(1) / \mathrm{SrCO}_{3}$ (orange line) before epoxidation at $\mathrm{F}=15 \mathrm{~mL} / \mathrm{min}, \mathrm{p}\left(\mathrm{C}_{3} \mathrm{H}_{6}\right)=\mathrm{p}\left(\mathrm{O}_{2}\right)=16.9 \mathrm{kPa}$ and $673 \mathrm{~K}$.

Figure 6 shows the maximum $\mathrm{CO}_{2}$-TPD peaks of $\mathrm{Ag}(56)-\mathrm{Na}(1) / \mathrm{SrCO}_{3}$ and $\mathrm{Ag}(75)$ $\mathrm{Na}(1) / \mathrm{SrCO}_{3}$ before the reactions at 733 and $723 \mathrm{~K}$, respectively, and the base amounts were estimated to be 0.048 and $0.009 \mathrm{mmol} / \mathrm{g}$, respectively. However, these $\mathrm{NH}_{3}$ - and $\mathrm{CO}_{2}$ TPD peaks had completely disappeared after the reaction, probably due to the formation of coking.

The characterization results shown above were somewhat of an analogue to the normal catalytic reaction regardless of the employment of the thermal- and photo-reactions when using solid catalysts. These results could not explain the advantageous effect that UV-LED irradiation exerted on $\mathrm{Ag}-\mathrm{Na} / \mathrm{SrCO}_{3}$ during the epoxidation of propylene to $\mathrm{PO}$. Therefore, we focused on the silver nano-particles that had formed when using the present catalyst system [7].

\subsection{Contribution of Silver Plasmon Excitation}

In our previous paper [7], we reported that nano-particles of silver with a wide distribution of particle sizes had formed on $\mathrm{Ag}(56)-\mathrm{Na}(1) / \mathrm{SrCO}_{3}$. With such a silver nanostructure, plasmon excitation forms excited electrons, which is thought to contribute to the 
catalytic oxidation on some metals $[10,11]$. In particular, electronic-state calculation of the catalytic oxidation of ethylene on silver nano-particles suggests that the transfer of excited electrons to gaseous oxygen to form active oxygen easily proceeds under silver plasmon excitation conditions [12]. However, since the lifetime of excited electrons is estimated to be very short, it is difficult for the excited electrons to directly transfer to the gas phase of oxygen. Recent studies have shown, however, that once excited electrons are generated on silver nano-particles, they tend to flow onto the support, and are then transferred to the gas phase of oxygen to form active oxygen [13-17]. In the present study, as shown in Table 1, $\mathrm{Ag}(56) / \mathrm{SrCO}_{3}$ and $\mathrm{Ag}(56)-\mathrm{Na}(1) / \mathrm{MgCO}_{3}$ showed no advantageous effect of UV-LED irradiation. This indicates that sodium-modified $\mathrm{SrCO}_{3}$ should be suitable as a support. The present results revealed that the latter suggestion may be supported if plasmonic excitation, which was confirmed on $\mathrm{Ag}(56)-\mathrm{Na}(1) / \mathrm{SrCO}_{3}$. Therefore, the steady-state absorption spectra of $\mathrm{Ag}(56)-\mathrm{Na}(1) / \mathrm{SrCO}_{3}$ was measured via an absorption spectroscopy. Figure 7 shows the Kubelka-Munk functions (K/S; K: absorption coefficient, S: scattering coefficient) obtained from the absorption spectra of $\mathrm{SrCO}_{3}$ and $\mathrm{Ag}(56)-\mathrm{Na}(1) / \mathrm{SrCO}_{3}$. Although there was no absorption from $\mathrm{SrCO}_{3}$ at wavelengths longer than $330 \mathrm{~nm}$, as reported [18], plasmon excitation via silver nano-particles was evident from $\mathrm{Ag}(56)-\mathrm{Na}(1) / \mathrm{SrCO}_{3}$ between 330 and $500 \mathrm{~nm}$. These are the same absorption regions reported for silver nano-particles [10], which was suitable for the present conditions using UV-LED at a wavelength of $365 \mathrm{~nm}$. The absorptions from $\mathrm{SrCO}_{3}$ and $\mathrm{Ag}(56)-\mathrm{Na}(1) / \mathrm{SrCO}_{3}$ observed at wavelengths shorter than $330 \mathrm{~nm}$ could be assigned to the bandgap excitation from $\mathrm{SrCO}_{3}[18,19]$.

Therefore, we concluded that the selectivity and yield of PO under UV-LED irradiation observed in the present study was improved when electrons derived from plasmon excitation on silver nanoparticles were transferred to the vapor phase of oxygen via the sodium-loaded support $\left(\mathrm{Na} / \mathrm{SrCO}_{3}\right)$ to generate an active oxygen corresponding to epoxidation.

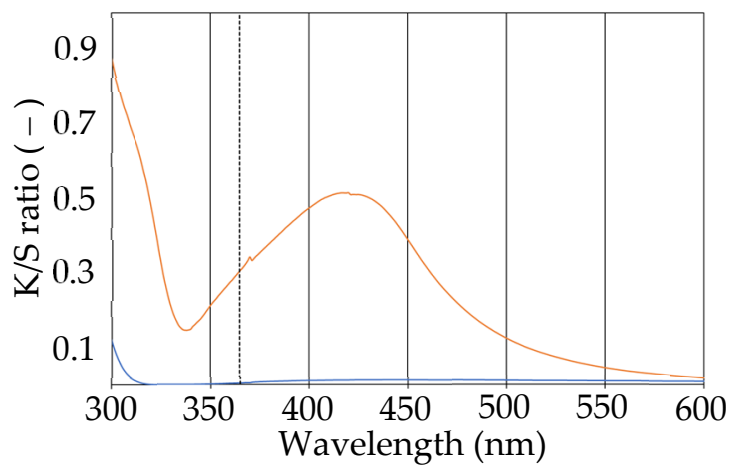

Figure 7. Kubelka-Munk functions of $\mathrm{SrCO}_{3}$ (blue line) and $\mathrm{Ag}(56)-\mathrm{Na}(1) / \mathrm{SrCO}_{3}$ (red line) obtained from the corresponding absorption spectroscopy.

\section{Materials and Methods}

\subsection{Catalyst Preparation}

Sodium-modified silver catalyst supported on strontium carbonate was prepared according to a method described in previous papers [7,9]. As a typical example, the preparation method for $\mathrm{Ag}(56)-\mathrm{Na}(1) / \mathrm{SrCO}_{3}$ (the numbers in parentheses refer to the weight \% loading of silver and sodium) is illustrated as follows. After ethylene diamine (15.0 g, $250 \mathrm{mmol}$; Kanto Chemical Co., Inc., Tokyo, Japan) was dissolved in distilled water (20.0 g), oxalic acid (10.1 g, 112 mmol; FUJIFILM Wako Pure Chemical Corp., , Tokyo, Japan) and $\mathrm{Ag}_{2} \mathrm{O}(8.90 \mathrm{~g}, 38.4 \mathrm{mmol})$ were slowly added to the aqueous solution with magnetic stirring for $1 \mathrm{~h}$. Then, ethanolamine (1.80 g, $29.5 \mathrm{mmol}$; Kanto Chemical Co., Inc.) and $\mathrm{NaCl}$ ( 0.147 g, $2.51 \mathrm{mmol}$; FUJIFILM Wako Pure Chemical Corp.) were dissolved in $4 \mathrm{~mL}$ distilled water and added to the aqueous solution. After the resultant mixture was stirred for an additional $1 \mathrm{~h}$, we added $6.40 \mathrm{~g}(43.4 \mathrm{mmol})$ of $\mathrm{SrCO}_{3}$ (FUJIFILM Wako Pure 
Chemical Corp.) to the mixture to form a slurry. The slurry was stirred for $4 \mathrm{~h}$ and dried at $393 \mathrm{~K}$ for $2 \mathrm{~h}$, followed by calcination at $633 \mathrm{~K}$ for $3 \mathrm{~h}$ to afford $\mathrm{Ag}(56)-\mathrm{Na}(1) / \mathrm{SrCO}_{3}$.

\subsection{Characterization of the Catalyst}

The catalysts were analyzed using nitrogen adsorption-desorption measurement (BELSORPmax12, MicrotracBEL, Osaka, Japan), X-ray diffraction (XRD; SmartLab/RA/ INP/DX, Ragaku Co., Tokyo, Japan), $\mathrm{NH}_{3}$ temperature-programed desorption ( $\mathrm{NH}_{3}-\mathrm{TPD}$; BELCAT II, MicrotracBEL), $\mathrm{CO}_{2}$ temperature-programed desorption $\left(\mathrm{CO}_{2}\right.$-TPD; BELCAT II, MicrotracBEL), scanning electron microscopy (SEM; JSM-6390, JEOL Ltd., Tokyo, Japan), and/or by using an absorption spectrophotometer (V-670, JASCO Co., Tokyo, Japan). Before the nitrogen adsorption-desorption measurement at $77 \mathrm{~K}$, each catalyst was pretreated at $473 \mathrm{~K}$ for $5 \mathrm{~h}$ under vacuum. The BET surface area was calculated from the obtained adsorption isotherm. The powder XRD patterns of the catalysts were obtained using monochromatized $\mathrm{Cu} \mathrm{K} \alpha$ radiation $(40 \mathrm{kV}, 150 \mathrm{~mA})$. The acidic or basic properties of the catalysts were measured using either $\mathrm{NH}_{3}-\mathrm{TPD}$ or $\mathrm{CO}_{2}$-TPD, both in which the pretreatment temperature was adjusted to $673 \mathrm{~K}$. The desorbed $\mathrm{NH}_{3}$ or $\mathrm{CO}_{2}$ from the catalyst was monitored using a BELMass (Microtrac-BEL) quadruple mass spectrometer with a mass signal of $\mathrm{m} / \mathrm{e}=16$ or 44 for $\mathrm{NH}_{3}$ or $\mathrm{CO}_{2}$, respectively. It should be noted that when $\mathrm{m} / \mathrm{e}=17$, this represented the mass signal of the $\mathrm{NH}_{3}$ parent peak, which was strongly influenced by $\mathrm{H}_{2} \mathrm{O}$, and, thereafter, $\mathrm{m} / \mathrm{e}=16$ was used for the analysis of $\mathrm{NH}_{3}$. The absorption spectrum of the catalyst was obtained by applying the Kubelka-Munk formula to the diffuse reflection spectrum.

\subsection{Evaluation of the Catalytic Performance}

The catalytic experiments were performed in a fixed-bed continuous-flow quartz reactor, which was placed in an electric furnace with an optical window, and operated at atmospheric pressure and $898 \mathrm{~K}$ [8]. As a light source for UV-LED irradiation, a Lightningcure LC-L1V3 (Hamamatsu Photonics K.K., Hamamatsu, Shizuoka) was used. This light source emits UV light at a wavelength of $365 \mathrm{~nm}$ for an average maximum irradiation intensity of $14,000 \mathrm{~mW} / \mathrm{cm}^{2}$ and a maximum output of $450 \mathrm{~mW}$. The temperature of the catalyst $(0.30 \mathrm{~g})$ was increased to $673 \mathrm{~K}$ under a flow of He. After the reaction temperature was stabilized, the catalyst was treated with a flow of $\mathrm{O}_{2}(15 \mathrm{~mL} / \mathrm{min})$ for $1 \mathrm{~h}$. Activity tests were then carried out under $15 \mathrm{~mL} / \mathrm{min}$ of a reactant gas flow $(\mathrm{F})$ that consisted of $\mathrm{C}_{3} \mathrm{H}_{6}$ and $\mathrm{O}_{2}$ diluted with $\mathrm{He}$. In the present study, a partial-pressure ratio of 1.0 was employed for $\mathrm{C}_{3} \mathrm{H}_{6} / \mathrm{O}_{2}$, and the partial pressures were then adjusted to $\mathrm{p}\left(\mathrm{C}_{3} \mathrm{H}_{6}\right) / \mathrm{p}\left(\mathrm{O}_{2}\right)=16.9 \mathrm{kPa} / 16.9 \mathrm{kPa}$, unless otherwise stated. Under these conditions, no homogeneous reactions were detected. The reaction was monitored using an on-line TCD gas chromatograph (GC-8APT, Shimadzu Corp., Kyoto, Japan) and an FID capillary gas chromatograph (GC-2010, Shimadzu Corp.). The columns in the TCD-GC consisted of a Molecular Sieve $5 \mathrm{~A}(0.3 \mathrm{~m} \times \Phi 3 \mathrm{~mm})$ for the detection of $\mathrm{O}_{2}, \mathrm{CO}$, and $\mathrm{CH}_{4}$ at $318 \mathrm{~K}$ and a Porapak Q (GL Sciences Inc., Tokyo, Japan, $6 \mathrm{~m} \times \Phi 3 \mathrm{~mm}$ ) for the detection of $\mathrm{CO}_{2}$, ethane, ethylene, propane, and propylene at column temperatures that ranged between 318 and $493 \mathrm{~K}$ with a heating rate of $10 \mathrm{~K} / \mathrm{min}$. Furthermore, the capillary column in the FID-GC consisted of Stabilwax (Shimadzu GLC Ltd., Tokyo, Japan, $60 \mathrm{~m} \times \Phi 0.25 \mathrm{~mm} \times 0.25 \mu \mathrm{m}$ ) for the detection of acetaldehyde, propylene oxide, propionaldehyde, acetone, acrolein, propane, and propylene at column temperatures of $313 \mathrm{~K}$. The conversion and the selectivity were estimated on a carbon basis.

\section{Conclusions}

In the present study, excited electrons generated via plasmonic silver on $\mathrm{Ag}-\mathrm{Na} / \mathrm{SrCO}_{3}$ under UV-LED irradiation contributed to an improvement in the selectivity and yield of propylene oxide through the catalytic epoxidation of propylene. A plausible explanation is that the electrons generated on the silver were transferred to the $\mathrm{SrCO}_{3}$ support doped with sodium where they reacted with gaseous $\mathrm{O}_{2}$ to form active oxygen suitable for epoxidation. 
The present study reveals the importance of paying attention to plasmonic excitation in addition to the usual focus on bandgap excitation during photocatalytic reactions on solid catalysts.

Author Contributions: Conceptualization and methodology, S.S., A.F., Y.K. and W.N.; validation, I.O., K.H., Y.M. and N.S.; formal analysis and investigation, S.S., I.O., K.H., Y.M. and N.S.; writingoriginal draft preparation, S.S. and A.F.; writing-review and editing, S.S., A.F., Y.K. and W.N.; supervision, S.S. All authors have read and agreed to the published version of the manuscript.

Funding: This research was supported by JSPS KAKENHI Grant Number JP20K05221 and by the Research Cluster Program of Tokushima University (1702001), for which we are grateful.

Data Availability Statement: All data are shown in this manuscript.

Conflicts of Interest: The authors declare no conflict of interest.

\section{References}

1. Kawabata, T.; Yamamoto, J.; Koike, H.; Yoshida, S. Trends and Views in the Development of Technologies for Propylene Oxide Production. RED Rep. "Sumitomo Kagaku" 2019, 1, 4-11.

2. Nijhuis, T.A.; Makkee, M.; Moulijin, J.A.; Weckhuysen, B.M. The Production of Propene Oxide: Catalytic Processes and Recent Development. Ind. Eng. Chem. Res. 2006, 45, 3447-3459. [CrossRef]

3. Tsuji, J.; Yamamoto, J.; Ishino, M.; Oku, N. Development of New Propylene Oxide Process. RED Rep. “Sumitomo Kagaku” 2006, 1, 1-8.

4. Ghosh, S.; Acharyya, S.S.; Tiwari, R.; Sarkar, B.; Singha, R.K.; Pendem, C.; Sasaki, T.; Bal, R. Selective Oxidation of Propylene to Propylene Oxide over Silver-Supported Tungsten Oxide Nanostructure with Molecular Oxygen. ACS Catal. 2014, 4, $2169-2174$. [CrossRef]

5. Zang, Q.; Chai, G.; Guo, Y.; Zhan, W.; Guo, Y.; Wang, L.; Wang, Y.; Lu, G. Gas-Phase Epoxidation of Propylene by Molecular Oxygen over Ag- $\mathrm{CuCl}_{2} / \mathrm{BaCO}_{3}$ Catalyst with Low $\mathrm{CuCl}_{2}$ Doping: Catalytic Performance, Deactivation and Regeneration. J. Mol. Catal. A. Chem. 2016, 424, 65-76. [CrossRef]

6. Khatib, S.J.; Oyama, S.T. Direct Oxidation of Propylene to Propylene Oxide with Molecular Oxygen: Review. Catal. Rev. 2015, 3 , 306-344. [CrossRef]

7. Sugiyama, S.; Sakuwa, Y.; Ogino, T.; Sakamoto, N.; Shimoda, N.; Katoh, M.; Kimura, N. Gas-phase Epoxidation of Propylene to Propylene Oxide on a Supported Catalyst Modified with Various Dopant. Catalysts 2019, 9, 638. [CrossRef]

8. Sugiyama, S.; Hayashi, Y.; Okitsu, I.; Shimoda, N.; Katoh, M.; Frube, A. Oxidative Dehydrogenation of Methane When Using $\mathrm{TiO}_{2}$ - or $\mathrm{WO}_{3}$-Doped $\mathrm{Sm}_{2} \mathrm{O}_{3}$ in the presence of Active Oxygen Excited with UV-LED. Catalysts 2020, 10, 559. [CrossRef]

9. Lu, J.; Bravo-Suárez, J.J.; Haruta, M.; Oyama, S.T. Direct Propylene Epoxidation over Modified Ag/CaCO 3 Catalysts. Appl. Catal. Gen. A. 2006, 302, 283-295. [CrossRef]

10. Christopher, P.; Xin, H.; Linic, S. Visible-light-enhanced Catalytic Oxidation Reactions on Plasmonic Silver Nanostructures. Nat. Chem. 2011, 3, 467-472. [CrossRef] [PubMed]

11. Kazuma, E.; Jung, J.; Ueba, H.; Trenary, M.; Kim, Y. Real-space and Real-time Observation of a Plasmon-induced Chemical Reaction of a Single Molecule. Science 2018, 360, 521-526. [CrossRef] [PubMed]

12. Takenaka, M.; Iwasa, T.; Taketsugu, T. Search for Reaction Pathway of Oxygen Dissociation Reaction Using Plasmon Catalyst. Abstract for Symposium for Reaction Path Search 2018 (SRPS 2018) 2018, 8. Available online: https://iqce.jp/SRPS /SRPS2018/ P8.pdf (accessed on 14 September 2018).

13. Furube, A.; Du, L.; Hara, K.; Katoh, R.; Tachiya, M. Ultrafast Plasmon-Induced Electron Transfer from Gold Nanodots into TiO 2 Nanoparticles. J. Am. Chem. Soc. 2007, 129, 14852-14853. [CrossRef] [PubMed]

14. Du, L.; Furube, A.; Hara, K.; Katoh, R.; Tachiya, M. Ultrafast Plasmon Induced Electron Injection Mechanism in Gold-TiO 2 Nanoparticle System. J. Photochem. Photobiol. C Photochem. Rev. 2013, 15, 21-30. [CrossRef]

15. Furube, A.; Hashimoto, S. Insight into Plasmonic Hot-electron Transfer and Plasmon Molecular Drive: New Dimensions in Energy Conversion and Nano fabrication. NPG Asia Mater. 2017, 9, e454. [CrossRef]

16. Okazaki, M.; Furube, A.; Chen, L.-Y. Charge Generation Dynamics in Hematite Photoanodes Decorated with Gold Nanostructures under Near Infrared Excitation. J. Chem. Phys. 2020, 152, 041106. [CrossRef] [PubMed]

17. Du, L.; Shi, X.; Zhang, G.; Furube, A. Plasmon Induced Charge Transfer Mechanism in Gold-TiO ${ }_{2}$ Nanoparticle Systems: The Size Effect of Gold Nanoparticle. J. Appl. Phys. 2020, 128, 213104. [CrossRef]

18. Wichannananon, P.; Kobkeatthawin, T.; Smith, S.M. Visible Light Responsive Strontium carbonate catalyst Derived from Solvothermal Synthesis. Catalysts 2020, 10, 1069. [CrossRef]

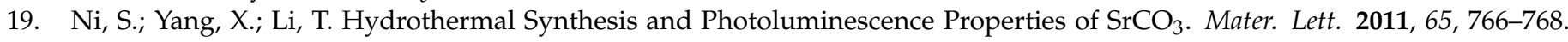
[CrossRef] 